procedure to what the present Board of Health of our great city of New York pretends to do!

The following are some of the examples:

Louis XIV, King of France, bought the following: Helvetius' Ipecac Remedy in 1686 at 1000 Louis d'or; Glauber's Kermes Mineral in 1720 at a fancy price; Talbor's Cinchona Remedy in 1780 at 2000 Guineas.

Louis XV bought the formula for La Mothe Tincture, giving him a pension of 4000 Livres a year.

Louis XVI purchased Mme. Nouffer's Tapeworm Remedy, at 18,000. Livres; King Charles II of England bought Dr. Goddard's Drops for 6000 pounds Sterling, and Empress Catharine II of Russia invested in Bestuscheff's Tincture, 3000 Rubles.

It will no doubt interest the readers of the Journal A. Ph. A. to learn of a striking example of the effects, the bad effects, of the publication of a formula. The specific is that of Warburg's Tincture.

Originated in 1840 by Dr. Carl Warburg, an Austrian physician, it soon proved to be a specific in Malaria and Ague. In spite of being a secret remedy, the Austrian Imperial Health Board in 1848 ordered this tincture to be kept in stock in all the pharmacies of the Empire, and even established at Vienna, a central depot at which the preparation was manufactured under the supervision of the inventor.

The fame of Warburg's Tincture spread as far as India, and it was considered as one of the necessities of all British soldiers going to that country. In consequence of this, the preparation obtained a tremendous sale. At last Dr. Warburg was persuaded, in fact pressed to disclose his secret formula. Warburg did so. What was the consequence? Warburg, the originator of the celebrated Antiperiodic Tincture, died in poverty.

The author does not claim that this subject is exhausted and hopes to be able in the near future to find the time to make a complete compilation of the origin, the history and the evolution of the U.S. P. and N. F. preparations.

\title{
THE RELATION BETWEEN MEDICINE AND PHARMACY.*
}

\section{WILFRED M. BARTON, M. D.,}

Associate Professor of Medicine in the Medical Department of Georgetown University.

In the first place, I shall take it that we are met here to-night, physicians and pharmacists, not merely for self glorification, but for the purpose of seriously discussing the true existing relations between our two professions, Medicine and Pharmacy; to find out whether we are drifting apart, developing a closer union, or merely maintaining a statu quo which we have inherited from our immediate

* Read at a joint meeting of the Therapeutical and Pharmaceutical Societies of Washington, D. C., June, 1914. 
predecessors. In any event we would like to know exactly what is the trend of affairs concerning our relations, the principal factors upon which this relation depends and, of course, we would like to find a way to improve these relations whatever they may be.

Primarily, I may say; what is no doubt evident to any one who thinks about it, that such a social re-union as this one to-night cannot but be productive of good results, because social intercourse between different, nay even differing interests, is the surest method of enhancing their mutual adjustment. We are, of course, not arbitrating anything, for it has not appeared that we have any differences to adjust; but the mere getting together of men engaged in related pursuits, is a sure way of enlarging their sympathies, and of widening their field of vision. What was before of only academic interest in the mind becomes vitalized by humanitarian and sentimental forces. We see not only a related science with all its technical accoutrements, but a brother human being working away and devoting his life to it. So, I would suggest, on this account, that such meetings as this be made more frequent and more general. The state pharmaceutical and medical societies should work out a plan of closer affiliation. When the American Medical Association meets annually in a certain place, there also and at the same time should the American Pharmacentical Association meet. Could this be done some very interesting events would take place, science would be advanced, disputes would be adjusted, professional ethics enlarged, quackery and charlatanism would receive blows from the effects of which they would sooner succumb. There is, however, one thing which serves at least periodically to bring physicians and pharmacists in this country closer together, and that is, the Pharmacopeia. The decennial revision of this great book, which has gone through eight editions, with a ninth one soon to appear, provides the only formal opportunity, at present indulged in, for closer affiliation and interchange of views between the two professions. The Committec on Revision, composed as it is of distinguished representatives from both, whose work extends over a period of years, tends to enlarge, to dignify, and to perpetuate, the bond of sympathy which exists between then.

It is always best to be methodical and if I were submitting any formal thesis upon the relations of Medicine to Pharmacy I should like to begin with a review of the historical aspects of this relation.

The phamnacopoeia forms the closest link between Medicine and Pharmacy. The scientific state of both at any given period, since the middle of the 16th century when the first pharmacoperia, that of Valerius Cordus, appeared (1540), may be read in its pages, and is reflected by its contents. The first London Pharmacopoia apjeared in 1618. It contained 1960 remedies, of which there were 1028 simples, 91 animal products and 271 vegetable products. There were some very strange substances in it, many of which to us now appear vile and disgusting, and it is hard for us to believe that intelligent men ever attributed therapeutic value to these things, such for example as worms, dried viper lozenges, dried fox's lung, powdered precious stones, oils of ants and wolves. The edition of 1650 contained moss from the skull of a victim of violent death, crab's eyes, animal feces, cock's comb, human perspiration, saliva of a fasting man, human placenta, wormian bones from executed criminals, and other itens too numerous 
to mention, and, certainly revolting, when one considers the proposition of swallowing them.

But even our present Pharmacopœia contains many useless, if not so disgusting, things, and if William Heberden, in 1745, was forced to make an onslaught upon the superstitions which retained animal feces and human placenta in the pharmacopœia in his day, and did not find it an easy proposition to secure their elimination, so also, at the present time, it is no easy matter to secure the deletion of many utterly worthless substances from the modern book. I often wonder whether future generations will not look down upon our far-famed ninth revision quite as ludicrously in some respects as we look back upon the English pharmacopoeias of 1650 . It is unfortunate, it seems to me, that the pharmaceutical factions who are concerned in revising our Codex, are usually opposed to the idea of deletion and use their influence toward the retention of substances in the book which to the modern physician who is acquainted with the progress of pharmacological and experimental therapeutic research seem entirely superfluous, and scientifically degrading. Those who are interested in this aspect of things we are discussing should read a paper by Doctor O. T. Osborne on "The Absurdities and the Commercialism of the Proposed 9th Decennial Revision of the U. S. Pharmacopœia." Though he does not say so categorically, yet by implication, the blame is put largely upon the Pharmaceutical representation in the executive committee on revision, eleven out of the sixteen of which are pharmacists. Out of one hundred and fifty-eight drugs and preparations, proposed to be deleted from the 9 th revision by the sub-committee on scope, seventynine were voted back by the pharmaceutical influences prevailing in the executive conmittee.

One of the great functions of the pharmacopoia is to keep constantly in view the close relations between Medicine and Pharmacy, which without it might by some be totally forgotten or ignored.

I had not intended to say so much about history and the pharmacopoia, but there is one more historical reference which will serve to clarify in a way, the reasons for the existence of a special feud between Medicine and Pharmacy which has been going on for about four hundred years. This is the dispute over the so-called "prescribing by druggists." According to history, the grocers were the original drug merchants in England. In 1606, during the reign of James. I, the apothecaries were incorporated, and succeeded in obtaining from the grocers this coveted monopoly. This aroused the ire of physicians, because, no sooner were the druggists invested with the power to compound and to sell all medicines, than they discovered that money could be made in easy fashion by selling direct to the people on their own responsibility. Thus began "drug dispensing" and with it a war which has continued, more or lessi openly, to the present day. Physicians and druggists continued to wrangle on this point in England for half a century, when, in 1665, the Great Plague broke out in London. The apothecaries stayed at their posts, while the doctors, including the great Sydenham himself, fled for their lives.

It seems that even at that time, however, the druggists were much criticized for their extortion, and the huge prices they charged for much worthless stuff may have been the origin of the erroneous idea, still prevailing among the laity, 
that the druggist makes anywhere from 500 to $1000 \%$ on his wares. On certain drug bills of the above-mentioned period in England, are listed 4s. for a glass of wine of iron, 3s. 6d. for a "purge for his worship," 3s. for a son's purge, $4 \mathrm{~s}$. for a fumigating powder. It is known that as much as 30s. was paid for one pill, and $6 \notin$ for a pill and a decoction. The pharmacists made more out of their cases than the physicians. But as a matter of fact we all know that extortion is not a monopoly of druggists and that some doctors have been known to indulge in a little of it, by way of exercise and showing what they can do.

There is no doubt that Pharmacy is receiving less and less attention in the medical curriculum at the present time. Does this mean that pharmacy is being gradually considered less and less important, to the educated medical man, or does it mean rather that pharmacy is developing so fast that it can no longer be properly covered, even synoptically, in a medical course? In this connection, we may profitably repeat what Cushny has written in his classical work on Pharmacology. He says "another subject which now occupies a much leșs prominent position in medical study than formerly is Pharmacy, or the art of preparing drugs for therapeutic use. Some general knowledge of the methods used, is no doubt indispensable to the educated physician, but the details may be left to the pharmacist. Pharmacy will probably occupy a still more subordinate position in medical education, as the tendency to include only one or two drugs in a prescription becomes more wide-spread. As long as a dozen or more components went to make one mixture, it was of importance to know their solubility and their interaction, but with the decay of the complex prescription the study of pharmacy by medical students has certainly become less imperative."

This appears to be a true representation of the facts, and it may have the effect of separating the physician and the pharmacist more and more, if some counter-acting influences are not called into play. It seems to me that all Colleges of Pharmacy should be closely affiliated with medical schools, just as the Dental school is closely associated. Dentistry bears the same relation to surgery that pharmacy does to medicine, and therefore the latter two should never be allowed to drift apart. The medical student is not expected to learn any dentistry, and according to Cushny and most modern pharmacologists, he should not be required to learn much pharmacy, but in order that all these cognate and corelated branches in our great medical science and art may thrive best, individually and collectively, and that the members of these sister professions may have a more adequate knowledge of their interdependence and corelation, they should all be taught in our universities as far as possible under the medical college roof. Here the great ideals which form the moral and ethical foundation of medicine can be inculcated, in the minds of all who are engaged in it, or any of its branches. Every hospital should have its expert pharmacist. Questions are continually arising which only a skilled chemist pharmacist can decide. I saw a good example of this fact in reading an article in a French journal recently by Crouzon on the use of ethero-camphorated oil. It seems that on the continent of Europe the old camphorated oil is much used, by hypodermic injection, in the treatment of senile pneumonia, collapse adynamia from diverse causes, shock, peritonitis, etc. Large doses are employed, 20 to $50 \mathrm{cc}$. more or less frequently repeated. These doses produce ugly lumps in the muscular tissues and even ab- 
cesses occur. Cruzon desired to know whether these disadvantages were inevitably inherent in the treatment itself, or whether they could be obviated by altering in some way the solution of the oil. This question he put to Viron, the expert pharmacist-chemist of the Saltpetriere Hospital, where both of them had worked. Viron suggested an ethero-oily solvent for the camphor in the following formula :

Camphor $\ldots \ldots \ldots \ldots \ldots \ldots \ldots \ldots \ldots \ldots \ldots \ldots \ldots \ldots \ldots \ldots$ gm.

Anesthetic Ether...................... $1 \mathrm{cc}$

Alcohol-washed sterilized olive oil............ $10 \mathrm{cc}$.

This solution, which must be prepared in a special way to prevent evaporation of ether, was found to be an agreeable substitute for the old solution and no lumps were formed. This, of course, is only a trivial example, but it illustrates the fact that there are certain problems in hospital work which can only be solved by the pharmacist, who is in this respect the true co-worker of the physician.

On the continent of Europe the colleges of pharmacy are regarded, and properly so, as integral parts of the University, and kept in closer affiliation with the medical schools than is attempted in the United States. There is no lack in number of pharmacy schools in this country, however. Although in 1840 there were only three, now there are about fifty. The student of pharmacy is often a college-bred man and the standard of pharmaceutical education is being gradually raised as in the medical schools.

It should be kept continually in mind, that pharmacy is a branch of medicine, a true specialty, and its teaching should always be conducted in colleges closely affiliated with medical schools. It will be seen thus, that our contention is, that the relation between Medicine and. Pharmacy is very close and must remain so. The science of medicine is founded upon anatomy, physiology and chemistry, while pharmacy is founded upon chemistry and physics. Progress in both depends, therefore, entirely upon progression in these fundamental sciences. Of course, from the standpoint of commercialism, there will be some disputes and antagonism between Medicine and Pharmacy, but from the standpoint of true science there can be but the closest union.

It is to be hoped that the standards of education in pharmacy will continue to be raised higher and higher commensurate with the developments in chemistry, pharmacy and medicine.

If this is done the pharmacist will become a still more indispensable associate of the physician especially in the direction of analytical and pharmaceutical chemistry and perhaps also pharmacology. Such meetings as the one we ate holding to-night will do good, affording as they do an opportunity of emphasizing what we should not allow to be forgotten, the close relation between the sciences of medicine and pharmacy. 